\title{
Determination of Parameters Useful for the Control of the Average Size of Pd Nanoparticles for C-Pd Composite
}

\author{
Kamil Sobczak
}

Received: 19 September 2013 / Accepted: 9 December 2014 / Published online: 23 December 2014 C) The Author(s) 2014. This article is published with open access at Springerlink.com

\begin{abstract}
Carbon-palladium composites have been investigated by the method of transmission electron microscopy. The composites have been obtained by two different processes: physical vapor deposition (PVD) and chemical vapor deposition (CVD). The relation between the average size of a palladium particle, the time, and temperature has been carried out. The samples were annealed at different temperatures - from $500{ }^{\circ} \mathrm{C}$ to $750{ }^{\circ} \mathrm{C}$ but also for three different times, that is, $5 \mathrm{~min}, 10 \mathrm{~min}$, and $30 \mathrm{~min}$. Activation energies were calculated from the Arrhenius equation. Obtained values for PVD and PVD/CVD samples are: $64.6 \mathrm{~kJ} \cdot \mathrm{mol}^{-1}$ and $38.8 \mathrm{~kJ} \cdot \mathrm{mol}^{-1}$, respectively. Determination of the activation energy will be useful in controlling the growth of palladium grains. Significant differences in values for both series resulted from encapsulation in graphite-palladium particles, which were obtained in the PVD/CVD process. Those graphite planes are formed at temperatures above $600{ }^{\circ} \mathrm{C}$ and significantly slow down the growth of palladium particles.
\end{abstract}

Keywords Chemical vapor deposition processes · C-Pd films · Nanomaterials · Physical vapor deposition processes

\section{Introduction}

Everything indicates that hydrogen will be probably one of the most important energy sources after the exhaustion of oil reserves. In addition to the standard chemical methods [1,2], innovative models and technologies for hydrogen are developing, such as alternative nuclear energy [3], geothermal energy [4,5], reactions based on photocatalysis [6], wind energy [7], and even processes with living organisms such as Citrobacter

K. Sobczak (凶)

Institute of Physics PAS, al.Lotników 32/46, 02668 Warsaw, Poland

e-mail:ksobczak@ifpan.edu.pl 
freundii [8]. Nowadays hydrogen and its compounds are commonly used in many fields of science and technology, for example, the Haber-Bosh process-the nitrogen fixation [9], and in the food industry-hydrogeneration [10]. Furthermore, science requires sensors to monitor the concentrations of hydrogen and hydrocarbonsionization chamber with $\mathrm{CH}_{4}$ [11], hydrogen-coolant [12], rocket fuel tanks [13], etc. To sum up, sensitive detectors of hydrogen and its compounds are sought in many branches of industry and science due to the fact that it became significant to control and monitor these gases since there is a huge risk to human life and property damage in case of leaks.

Investigated films can be used as the active layer of hydrogen and hydrocarbon detectors. The use of palladium, for which the ability to absorb hydrogen has been known for many years [14], and porous carbon, which is characterized by a large specific surface area [15], significantly increases the detection ability of hydrogen and leads to creation of an ideal detector of hydrogen.

Tests showed that palladium nanoparticles also have the ability of trapping hydrogen $[16,17]$ and changing its electrical conductivity [18]. The main aim of this study was to determine the accurate activation energy $\left(E_{\mathrm{a}}\right)$ of the palladium grains' growth process, in order to control their size. It is crucial to observe differences in the absorption of hydrogen, which depend on the size of Pd grains [19], the relation between the size of grains and the sensor response, the time response, and resistance to $\mathrm{CO}$ poisoning [20,21]. Therefore, knowledge of the $E_{\mathrm{a}}$ of palladium grains' growth helps to control their size, which is crucial in the active layers of a hydrogen detector.

\section{Experimental}

\subsection{Sample Preparation}

In the PVD process, fullerenes and palladium atoms were deposited on $\mathrm{Al}_{2} \mathrm{O}_{3}$ or $\mathrm{Si}$ under a dynamic pressure of $10^{-5} \mathrm{mbar}$. Two separate sources were used: one containing fullerene $\mathrm{C}_{60}$ powder $(99.9 \%)$ and the second with palladium acetate $\operatorname{Pd}\left(\mathrm{C}_{2} \mathrm{H}_{3} \mathrm{O}_{2}\right)_{2}$.

During the deposition process, the temperature of the substrates was $\sim 100^{\circ} \mathrm{C}$ and the time of growth was a few minutes. Then some of the PVD samples have been annealed at temperatures of $(500,550,600,650,700$, and 750$){ }^{\circ} \mathrm{C}$. Other samples were modified by the CVD method over the same range of temperatures. During the second process, a decomposition of xylene over the film surface occurred. A structure containing Pd nanograins embedded in amorphous carbon was obtained. Detailed information about these processes can be found in [22,23]. In both processes, three series of samples of PVD and PVD/CVD, which were annealed for three different times: $(5,10$, and 30) min have also been prepared.

\subsection{Research Methods}

TEM investigations: high-resolution TEM (HRTEM), dark field (DF), and selected area electron diffraction (SAED) were carried out using a JEOL JEM 2000 EX at $200 \mathrm{kV}$ 
and Titan Cubed 80-300 at 300 kV. The specimens were prepared by mechanical stripping of the layer on a 1000 mesh grid. The lamellas from both samples were prepared using the focus ion beam (FIB) from Helios NanoLab 600i. First, the film surface has been protected by the platinum layer. Then the protected layer was cut out by using a gallium ion beam. This method was not destructive for the platinum protected part of the samples. Finally, the lamella was soldered to the standard Omniprobe Lift-Out grids.

\section{Theoretical Introduction}

The palladium grain-growth mechanism of the physical vapor deposition method is extensively investigated with regard to both experimental and theoretical methods. For the theoretical simulation, two methods are used most commonly: molecular dynamics [24] and Monte Carlo [25]. It is assumed that the dominant process in the formation of Pd grains is carried out via diffusion and aggregation [26]. However, it is related to the silicon substrate without the presence of carbon. Unfortunately, the analysis of the growth of the palladium particles in a carbonaceous matrix is so far a process too complex for theoretical considerations due to the diversity of the carbon that is formed in such a layer. In the investigated films, in addition to the porous carbon, graphite [37], fullerenes, [27] and fullerite [28] are observed. In the initial stage of growth of the Pd particles, clusters are formed from the gas phase [29]. The critical size of these clusters is not well defined in the literature. However, magic numbers are often mentioned and they correspond to the most common number of atoms that create these clusters. Such palladium may take the form of a great number of geometric forms such as octahedrons, hexahedrons, hexoctahedrons, decahedrons, and square dipyramid form [30]. Studies that have been carried out with TEM and X-ray diffraction [31] on layers of our PVD showed the existence of $\mathrm{Pd}_{n} \mathrm{C}_{60}$ metallofullerenes. These structures were predicted by Loboda et al. [32] and were described as exohedral metallofullerenes. A quite strong argument for the diffusive nature of the palladium particle growth is the fact that after annealing, the sample series obtained after the CVD process at different temperatures showed no changes in the nature of the curve in the graph of temperature versus size (more about this in the results). This excludes Ostwald ripening type processes [33] since it is known that a graphite shell is created at temperatures of $\sim 650^{\circ} \mathrm{C}$. Also, the merging of smaller grains and their recrystallization are observed and, in the end, it results in the formation of polycrystalline grains - however, this applies only to grains after the CVD process and it dominates at long annealing times.

To determine the activation energy for palladium crystallites, the Arrhenius formula was used [34]:

$$
K=A \exp \left(-E_{\mathrm{a}} /(R T)\right)
$$

Here $E$ denotes the activation energy, $R$ is the universal gas constant, $K$ is the rate constant, and $A$ denotes a reaction constant called the Arrhenius prefactor.

And with the relation [35],

$$
D^{m}-D_{\mathrm{o}}^{m}=K t
$$

which can be represented as 


$$
\ln (D)=1 / m \ln (K)+1 / m \ln (t)
$$

where $D$ is the average grain size, $D_{\mathrm{o}}$ is the average size at $t=0$, is neglected, and $1 / m=n$.

We obtain [36]

$$
D=K t^{n} \exp \left(-E_{\mathrm{a}} / R T\right)=A_{0} \exp \left(-E_{\mathrm{a}} /(R T)\right)
$$

which can be represented as

$$
\ln (D)=\ln A_{0}-E_{\mathrm{a}} /(R T) .
$$

\section{Results}

The first micrograph (Fig. 1) shows focused ion beam (FIB) cross sections of the films that were obtained in the PVD and PVD/CVD processes with thicknesses and descriptions of each layer. Further information can be found in Sobczak et al. [37]. Micrographs for PVD samples annealed for three different times are shown in Fig. 2. A histogram (Fig. 3) that was created on the basis of the micrograph in Fig. 2, presents the size of nanoparticles from the investigated samples. Additionally, in the histogram in Fig. 3, the fitted log-normal distributions are plotted and, as a result, an average grain size was determined. The same procedure was carried out for PVD/CVD films. Figure 4 shows the investigated films (images taken with dark field technique), and Fig. 5 presents histograms that correspond to them. The temperature-dependent size curve is similar to the one for the PVD process, just as was observed for other metals annealed in the carbonaceous matrix at various temperatures-for example, Pt nanoparticles [38].

A significant difference in the average crystallite size of palladium in the samples of PVD/CVD results from the existence of a graphite shell. The shell is formed around

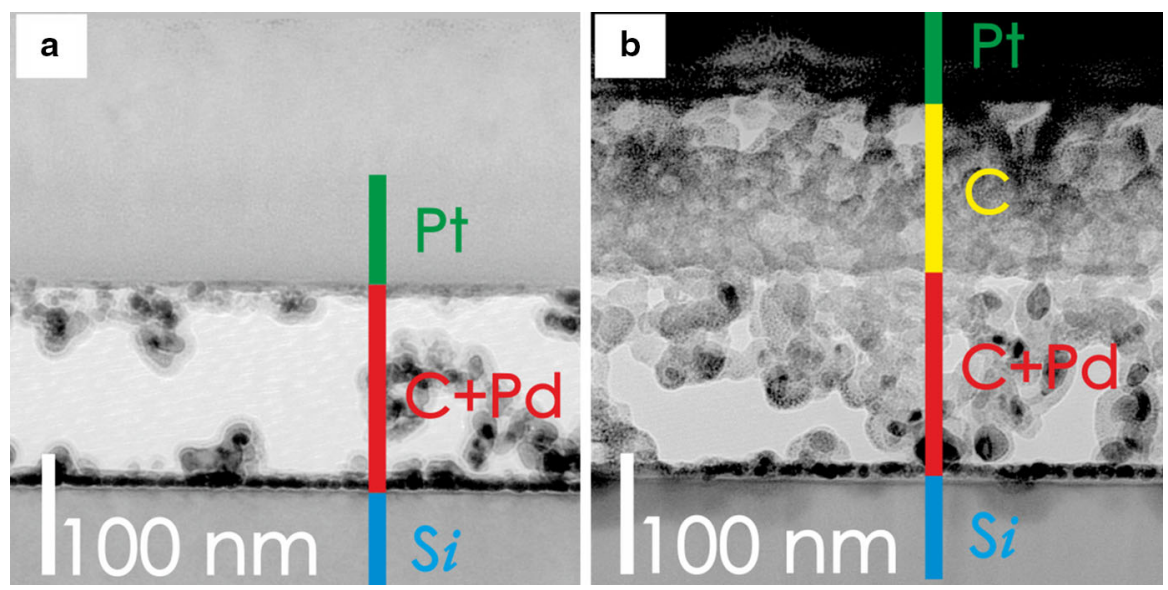

Fig. 1 Cross sections (lamella) of the films obtained in (a) PVD and (b) PVD/CVD processes 

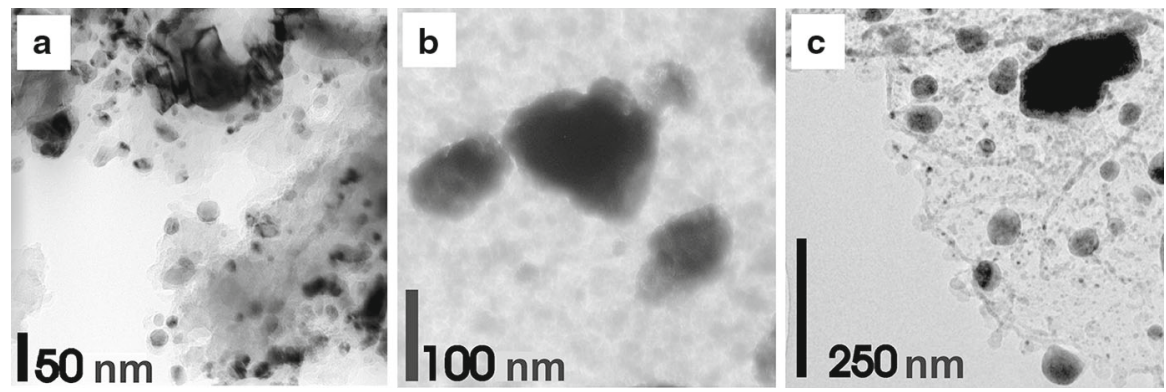

Fig. 2 Views of PVD films for samples annealed for (a) $5 \mathrm{~min}$, (b) $10 \mathrm{~min}$, and (c) $30 \mathrm{~min}$ at $650^{\circ} \mathrm{C}$
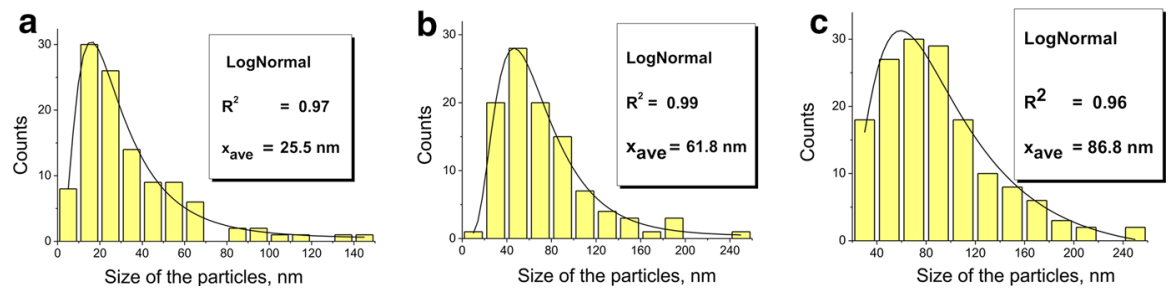

Fig. 3 Histograms for samples of PVD films annealed for (a) $5 \mathrm{~min}$, (b) $10 \mathrm{~min}$, and (c) $30 \mathrm{~min}$
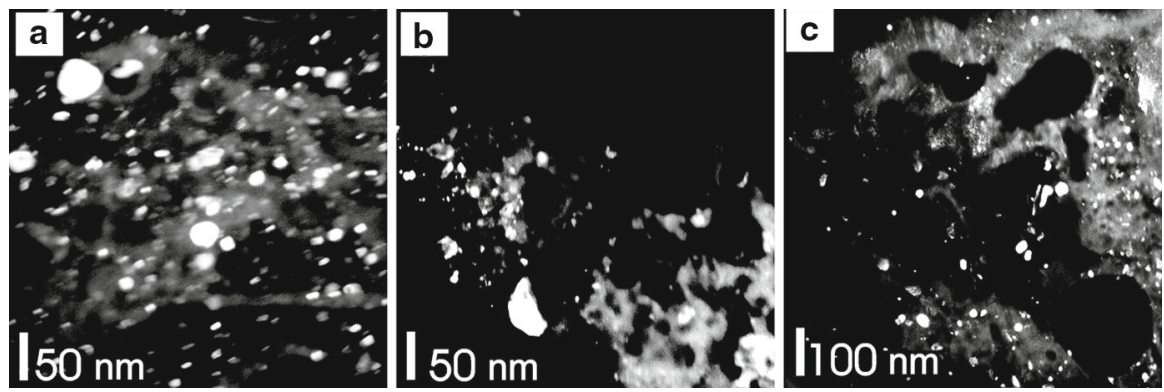

Fig. 4 View of PVD/CVD films for samples annealed for (a) $5 \mathrm{~min}$, (b) $10 \mathrm{~min}$, and (c) $30 \mathrm{~min}$ at $650^{\circ} \mathrm{C}$
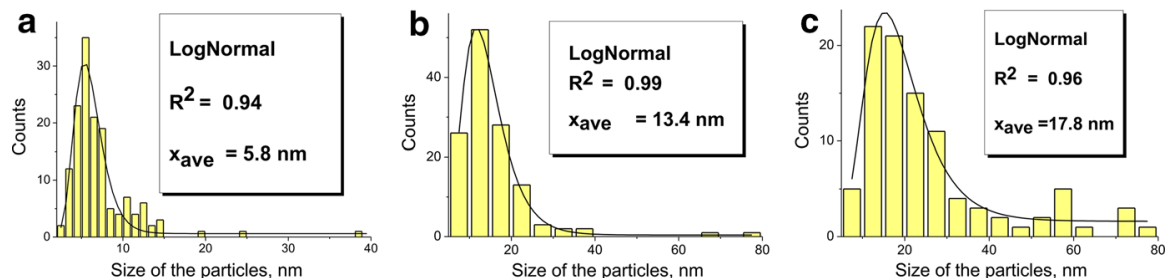

Fig. 5 Histograms for samples of PVD/CVD films annealed for (a) $5 \mathrm{~min}$, (b) $10 \mathrm{~min}$, and (c) $30 \mathrm{~min}$

palladium at temperatures above $600^{\circ} \mathrm{C}$ as a result of the decomposition of the organic fraction (e.g., xylene), which is clearly visible in the separation of the curves in Fig. 6 at a temperature around $600{ }^{\circ} \mathrm{C}$. The authors [39] reported that the surfaces of graphite 


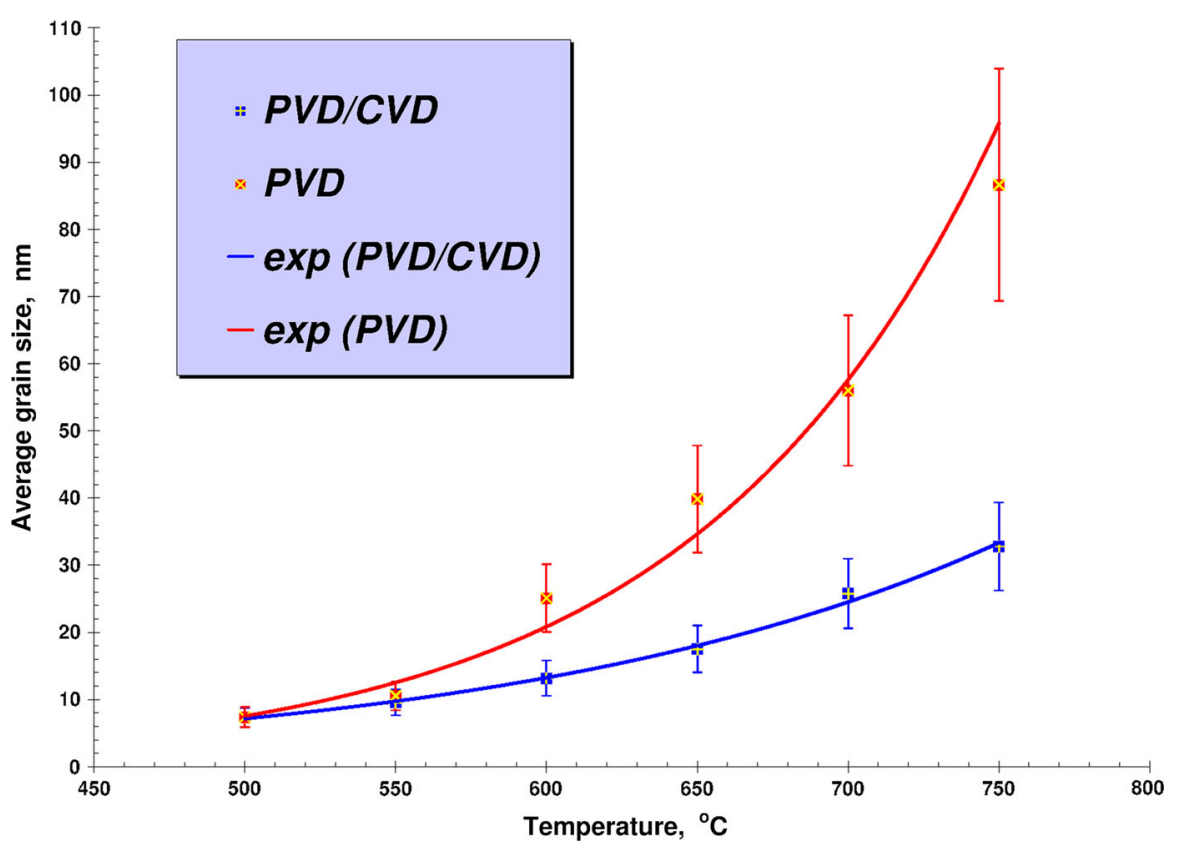

Fig. 6 Plot of $D$ versus $T$ for both types of samples of PVD and PVD/CVD
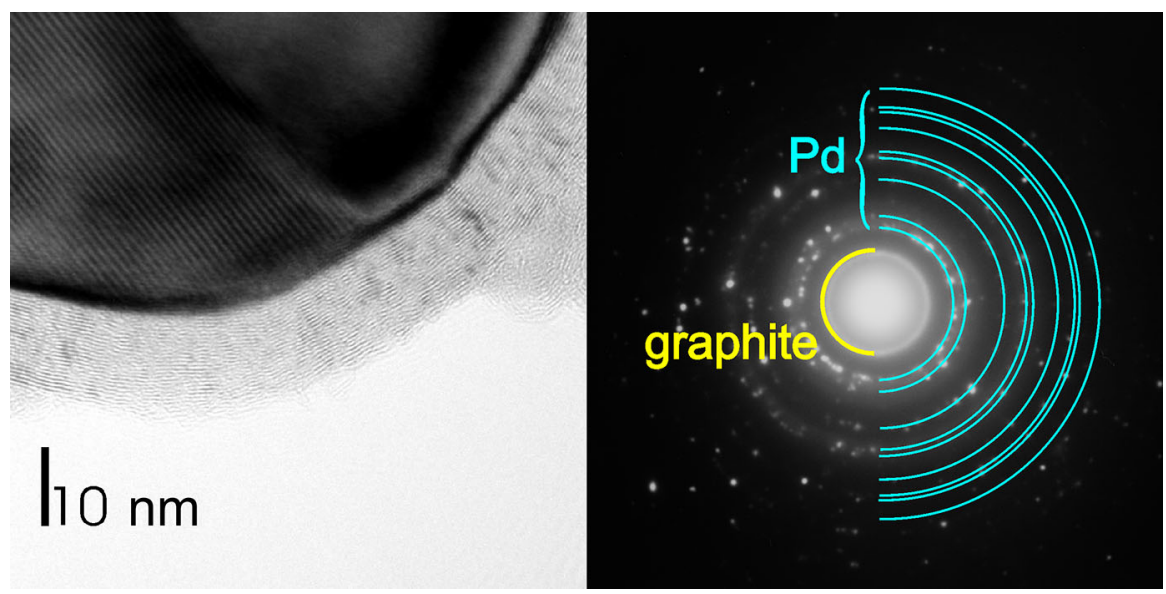

Fig. 7 Palladium nanocrystallite together with a graphite shell and electron diffraction with identification rings

can be created from a wide range of organic materials in the CVD process. Palladium with the graphite shell also reveals optical activity in the visible range [40].

Figure 7 shows the graphite shell together with the diffraction, which confirms the existence of graphite.

Using the formula (Eq. 3), the grain-growth exponents for both types of samples obtained for the PVD value of $n_{\mathrm{PVD}}=1.6 \pm 0.4$ and the PVD/CVD value of $n_{\mathrm{CVD}}=$ $2.5 \pm 0.3$ were determined. 


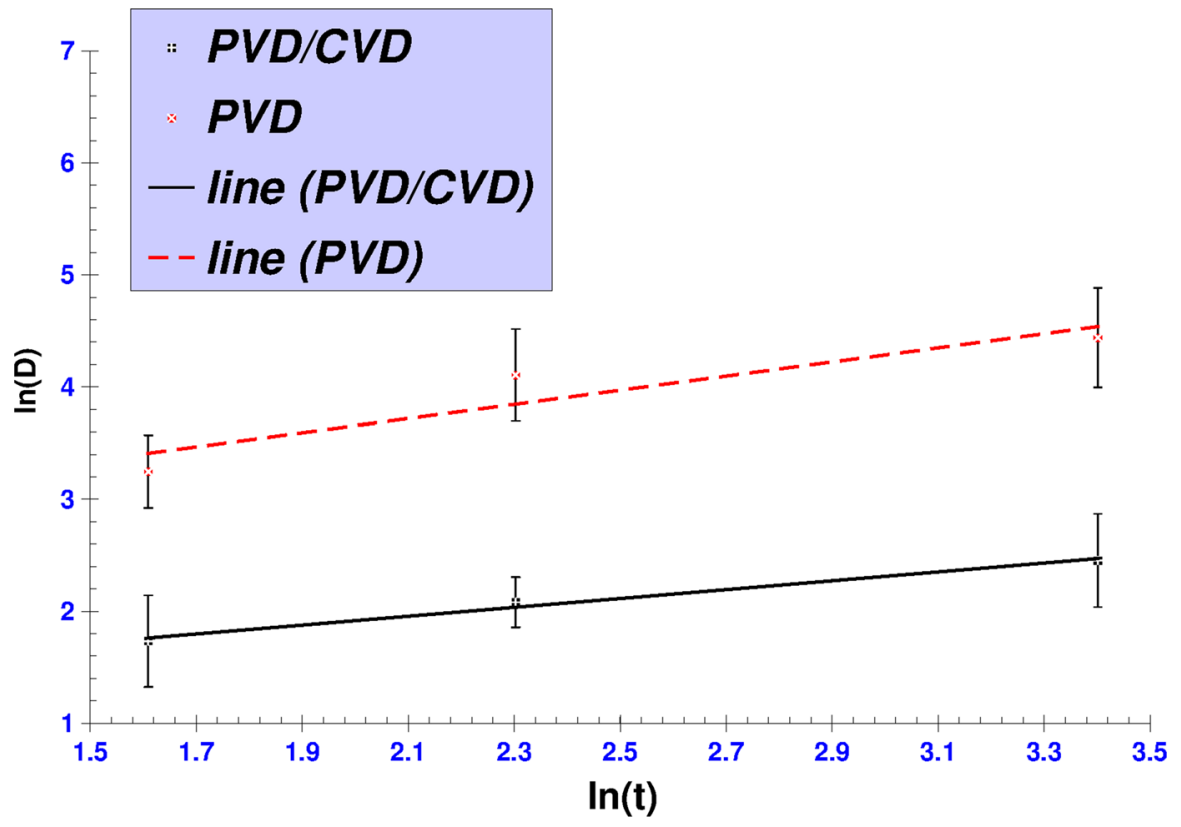

Fig. 8 Plot of $\ln (D)$ versus $\ln (t)$; slope gives the value of growth exponent

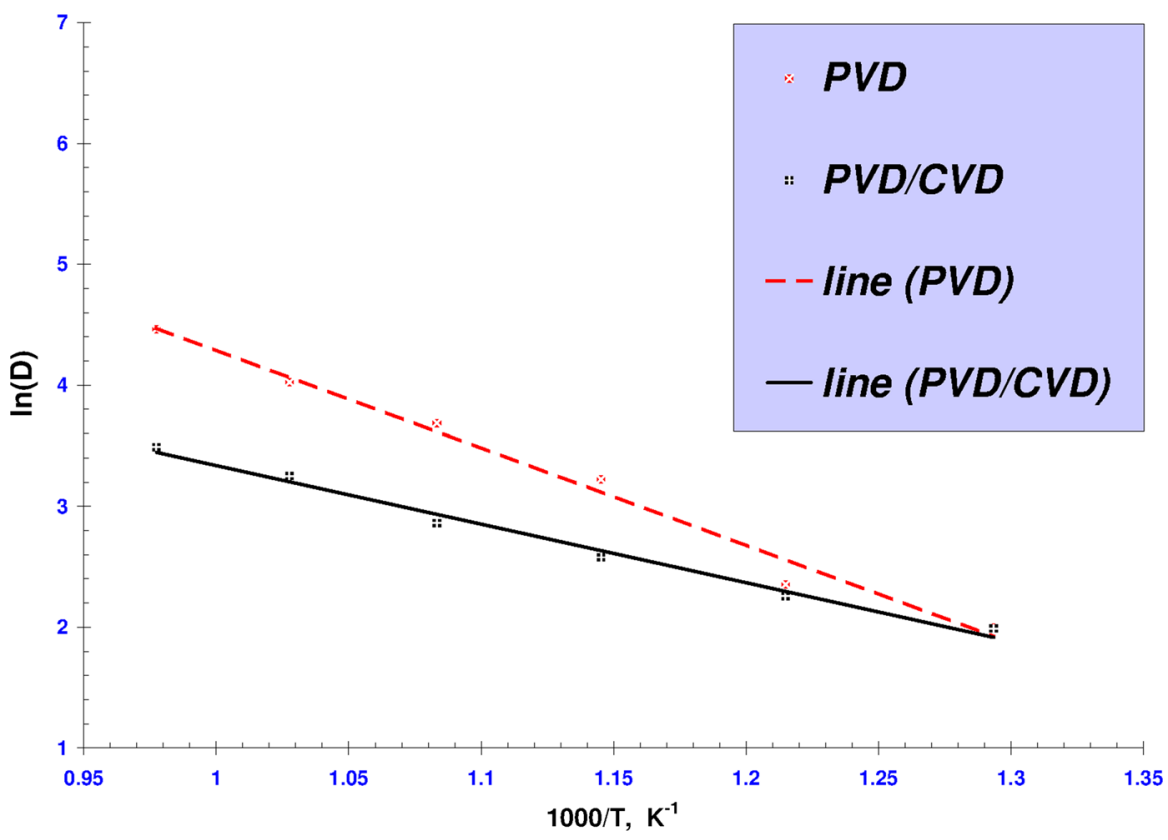

Fig. 9 Plot of $\ln (D)$ versus $1 / T$; slope gives information about the activation energy for grain growth 
Figure 8 shows a graph obtained from the formula (Eq. 3). For samples obtained in the PVD process, the calculated value was close to 2 , which is only observed in highpurity elements such as $\mathrm{Cd}, \mathrm{Fe}$, and $\mathrm{Sn}$ [41]. In the case of PVD/CVD, a deviation from 2 was observed, which was not surprising due to the presence of the graphite shell.

Then the dependence of the growth of an average palladium particle size as a function of temperature was examined. For both types of samples, a relation described by an exponential function (Fig. 6) was obtained. The graph in Fig. 9 presents the results of using Eq. 5. The obtained activation energy values are: $E_{\mathrm{aPVD}}$ : $(64.6 \pm$ $1.1) \mathrm{kJ} \cdot \mathrm{mol}^{-1}$ and $E_{\mathrm{aCVD}}:(38.8 \pm 0.9) \mathrm{kJ} \cdot \mathrm{mol}^{-1}$. For pure palladium similar values of $36 \mathrm{~kJ} \cdot \mathrm{mol}^{-1}$ [42] or $34.8 \mathrm{~kJ} \cdot \mathrm{mol}^{-1}$ [43] were measured. An increase in the activation energy was observed for palladium, which is poisoned or contains a dopant $-(35.3 \pm$ 3) $\mathrm{kJ} \cdot \mathrm{mol}^{-1}$ (pure Pd) to $(55 \pm 11) \mathrm{kJ} \cdot \mathrm{mol}^{-1}$ (sulfur-saturated palladium) [44]. In our investigation, we had two types of Pd grains: in porous and amorphous carbon (samples after the PVD process) and the grains of palladium with the graphite shell, which were also embedded in porous carbon (sample after PVD/CVD process).

\section{Conclusions}

The grains' growth exponent in Pd nanocrystalline materials has been determined. A difference was noted between the size of palladium in the samples after the PVD and CVD processes, which explained the existence of a graphite shell.

Due to the fact that the graphite-palladium structure is a conductor of electricity, it can serve as a detector of hydrogen. In addition, a graphite shell can prevent the palladium compounds from poisoning by $\mathrm{CO}$ or other chemical compounds, and also can help to react properly to the presence of hydrogen.

The activation energy from the Arrhenius formula was determined. The obtained activation energy values were: $E_{\mathrm{aPVD}}:(64.6 \pm 1.1) \mathrm{kJ} \cdot \mathrm{mol}^{-1}$ and $E_{\mathrm{aCVD}}:(38.8 \pm$ $0.9) \mathrm{kJ} \cdot \mathrm{mol}^{-1}$. Determined values will be helpful to control the average size of the palladium, because we have determined the relationship between an average size of the Pd grain and the resistance of the film [45]. It is very important for obtaining a valuable sensor of hydrogen molecules.

Acknowledgments This research was co-financed by the European Regional Development Fund within the Innovative Economy Operational Programme 2007-2013 ("Development of technology for a new generation of the hydrogen and hydrogen compounds sensor for applications in above normative conditions," No. UDA-POIG. 01.03.01-14-071/08-06 and "Analytical high resolution transmission electron microscope for nanoscience, nanotechnology and spintronics" No. POIG.02.01-00-14-032/08). The author would also like to thank Mrs. J. Radomska and Mrs. H. Wronka for preparing samples.

Open Access This article is distributed under the terms of the Creative Commons Attribution License which permits any use, distribution, and reproduction in any medium, provided the original author(s) and the source are credited.

\section{References}

1. N. Ozalp, Int. J. Hydrogen Energy 33, 5020 (2008)

2. Q.-L. Meng, C.-I. Lee, H. Kaneko, Y. Tamaura, Thermochim. Acta 532, 134 (2012) 
3. B. Yildiz, M.S. Kazimi, Int. J. Hydrogen Energy 31, 77 (2006)

4. M. Kanoglu, A. Bolatturk, C. Yilmaz, Int. J. Hydrogen Energy 35, 8783 (2010)

5. M.T. Balta, I. Dincer, A. Hepbasli, Int. J. Hydrogen Energy 35, 138 (2010)

6. B. Zielińska, E. Borowiak-Palen, R.J. Kalenczuk, J. Phys. Chem. Solids 72, 117 (2011)

7. R.J. Mantz, H. De Battista, Int. J. Hydrogen Energy 33, 4291 (2008)

8. T.M. Vatsala, Int. J. Hydrogen Energy 17, 923 (1992)

9. G. Ertl, J. Vac. Sci. Technol. A 1, 1247 (1983)

10. M. Hudlický, Reductions in Organic Chemistry, 2nd edn. (American Chemical Society, Washington, DC, 1996)

11. J. Andrzejewski, Y.M. Gledenov, A. Korejwo, K. Sobczak, P.J. Szalanski, Nukleonika 52, 51 (2007)

12. H. Subramanian, S. Velmurugan, S.V. Narasimhan, Can. J. Chem. Eng. 91, 344 (2013)

13. D.K. Huzel, D.H. Huang, Modern Engineering for Design of Liquid-Propellant Rocket Engines, 2nd edn. (AIAA, Washington, DC, 1992)

14. T. Graham, Philos. Trans. R. Soc. 156, 426 (1866)

15. G.P. Meisner, Q. Hu, Nanotechnology 20, 204023 (2009)

16. P. Ferrin, S. Kandoi, A.U. Nilekar, M. Mavrikakis, Surf. Sci. 606, 679 (2012)

17. H. Natter, B. Wettmann, B. Heisel, R. Hempelmann, J. Alloys Compd. 253-254, 84 (1997)

18. R.K. Joshi, S. Krishnan, M. Yoshimura, A. Kumar, Nanoscale Res. Lett. 4, 1191 (2009)

19. A. Züttel, Ch. Nützenadel, G. Schmid, D. Chartounia, L. Schlapbach, J. Alloys Compd. 293-295, 472 (1999)

20. J. Ravi Prakash, A.H. McDaniel, M. Horn, L. Pilione, P. Sunal, R. Messier, R.T. McGrath, F.K. Schweighardt, Sens. Actuators B 120, 439 (2007)

21. M.K. Kumar, M.S. Ramachandra, R.S. Ramaprabhu, J. Phys. D 39, 2791 (2006)

22. A. Kamińska, S. Krawczyk, M. Kozłowski, E. Czerwosz, K. Sobczak, Sens. Lett. 11, 500 (2013)

23. E. Kowalska, E. Czerwosz, M. Kozłowski, W. Surga, J. Radomska, H. Wronka, J. Therm. Anal. Calorim. 101, 737 (2010)

24. P.B. Balbuena, J.M. Seminario, eds., Molecular Dynamics, From Classical to Quantum Methods (Theoretical and Computational Chemistry), 1st edn., vol. 7 (Elsevier, Amsterdam, 1999)

25. P. Jensen, Rev. Mod. Phys. 71, 1695 (1999)

26. V. Agarwal, I. Aruna, V. Banerjee, B.R. Mehta, Phys. Rev. B 74, 035412 (2006)

27. J. Rymarczyk, A. Kamińska, J. Kęczkowska, M. Kozłowski, E. Czerwosz, Opt. Appl. 43, 123 (2013)

28. A. Kamińska, S. Krawczyk, E. Czerwosz, K. Sobczak, M. Kozłowski, Sens. Actuators A 196, 86 (2013)

29. Z.L. Wang, J. Phys. Chem. B 104, 1153 (2000)

30. G.U. Kulkarni, P.J. Thomas, C.N.R. Rao, Pure Appl. Chem. 74, 1581 (2002)

31. E. Czerwosz, R. Diduszko, P. Dłużewski, J. Kęczkowska, M. Kozłowski, J. Rymarczyk, M. Suchańska, Vacuum 82, 372 (2007)

32. O. Loboda, V.R. Jensen, K.J. Borve, Nanotub. Carbon Nanostruct. 14, 365 (2006)

33. I.M. Lifshitz, V.V. Slyozov, J. Phys. Chem. Solids 19, 35 (1961)

34. T. Gancarz, W. Gasior, H. Henein, Int. J. Thermophys. 34, 250 (2013)

35. F. Liu, G. Yang, H. Wang, Z. Chen, Y. Zhou, Thermochim. Acta 443, 212 (2006)

36. Y. He, Thermochim. Acta 546, 143 (2012)

37. K. Sobczak, P. Dłużewski, M.T. Klepka, B. Kurowska, E. Czerwosz, Int. J. Hydrogen Energy 37, 18556 (2012)

38. E. Prestat, R. Popescu, H. Blank, R. Schneider, D. Gerthsen, Surf. Sci. 609, 195 (2013)

39. M. Yudasaka, R. Kikuchi, T. Matsui, Y. Ohki, M. Baxendale, S. Yoshimura, E. Ota, Thin Solid Films 305, 351 (1997)

40. K. Sobczak, P. Dluzewski, B.S. Witkowski, J. Dąbrowski, M. Kozlowski, E. Kowalska, E. Czerwosz, Solid State Phenom. 186, 177 (2012)

41. C. Suryanarayana, C.C. Koch, Hyperfine Interact. 130, 5 (2000)

42. C.W. Corti, Platin. Met. Rev. 30, 184 (1986)

43. B.D. Eley, P. Luetic, Trans. Faraday Soc. 53, 1483 (1957)

44. F.J. Castro, G. Meyerb, G. Zampieric, J. Alloys Compd. 330-332, 59 (2002)

45. W. Bielski, A. Idzik, P. Kowalczyk, E. Czerwosz, J. Rymarczyk, AIP Conf. Proc. 1558, 2193 (2013) 